\title{
An Analysis of the Problems Users Experience in Public Health Care Facilities in Trinidad and Tobago
}

\author{
Bennie Berkeley \\ University of Trinidad and Tobago, Wallerfield, Trinidad and Tobago \\ Email: bennieberkeley8@gmail.com
}

How to cite this paper: Berkeley, B. (2019) An Analysis of the Problems Users Experience in Public Health Care Facilities in Trinidad and Tobago. Open Access Library Journal, 6: e5364.

https://doi.org/10.4236/oalib.1105364

Received: April 2, 2019

Accepted: July 21, 2019

Published: July 24, 2019

Copyright $\odot 2019$ by author(s) and Open Access Library Inc.

This work is licensed under the Creative Commons Attribution International License (CC BY 4.0).

http://creativecommons.org/licenses/by/4.0/

\begin{abstract}
This paper is based on research that aimed to understand the main problems or challenges affecting users of public healthcare facilities in Trinidad and Tobago. The research utilized the Generic Qualitative Method (GQM) with a sample of 20, mainly female participants who self-identified as being lower class or lower middle class. Its purpose was to perform a partial SWOT or $\mathrm{W}$-analysis by exploring perceived weaknesses in the public healthcare system. The research was conducted in East Trinidad and analyzed participants' actual or vicarious experiences. Four main problems/challenges were identified: long waiting time, inadequate health financing, poor maintenance, and social inequality. All four challenges were interrelated and were explained in terms of the "primary effects of social stratification"; that is users' low status position in society. "Primary effects of stratification" implies that users waited longer on health providers (doctors and nurses) in health facilities that users perceived received too little state funding. This is evidenced by participants' claim that public health facilities were poorly maintained and that there was acute shortage of efficiently functioning medical technology. Increased spending on public health care was thought to be the main solution to this country's health care problems.
\end{abstract}

\section{Subject Areas}

Public Health

\section{Keywords}

Public Healthcare, Partial SWOT Analysis, Primary Effects of Stratification

\section{Introduction}

The introduction will examine five issues: a definition of the "primary effects of 
stratification", interrelationship between low class/income and ill-health, improvement in the Human Development Index (HDI) and the persistence of healthcare challenges in Trinidad and Tobago, structure of Trinidad and Tobago's health system, and a definition of SWOT analysis and partial SWOT analysis.

"Primary effects of stratification" means that individuals with better jobs, higher incomes, better education and higher status who live in wealthier areas will live longer and healthier lives, (Praeg [1]). In other words, they enjoy superior life chances to those with less well-paying jobs, lower education and lower classs tatus who reside in less wealthy areas. As a consequence, the lower class have lower life expectancy. In terms of health, the "primary effects of stratification" implies that individuals in higher classes will receive better healthcare than their lower class counterparts. Overall, it may be argued that structural and cultural factors such as physical conditions and health professional work attitude respectively are less beneficial to the healthcare needs of the poor and less privileged.

Membership in low income groups, living in poverty and experiencing ill-health are intertwined. This is the case both within and between countries. Within countries, poor people have worse health outcomes than better-off people. This association reflects causality running in both directions as poverty breeds ill-health, and ill-health keeps poor people poor, (Wagstaff [2]). It is also argued that within countries poverty and poor health are inextricably linked. The causes of poor health for millions globally are rooted in political, social and economic injustices. In turn, poor health traps communities in poverty. Infectious and neglected tropical diseases kill and weaken millions of the poorest and most vulnerable people each year, (Roberts [3]). Additionally, it is argued that people in poor countries tend to have worse health outcomes than people in richer countries.

According to the United Nation's Development Program UNDP [4], Trinidad and Tobago's HDI value for 2017 was 0.784 - which put the country in the high human development category-positioning it at 69 out of 189 countries and territories. Between 1990 and 2017, Trinidad and Tobago's HDI value increased from 0.672 to 0.784 , an increase of 16.7 percent. Between 1990 and 2017, Trinidad and Tobago's life expectancy at birth increased by 2.8 years, mean years of schooling increased by 3.0 years and expected years of schooling increased by 1.7 years. Trinidad and Tobago's GNI per capita increased by about 153.5 percent between 1990 and 2017, (UNDP [4]). In spite of these improvements, the country faces healthcare challenges that can be examined in terms of the inverse care law, a theory developed by (Hart [5]).

Hart [5] claims that the availability of good medical or social care tends to vary inversely with the need of the population served. The inverse care law proposes that the poor who need healthcare more, receive it less than their wealthier counterparts. Evidence in Trinidad and Tobago supports the inverse care law. In 
Trinidad and Tobago, the real problem is the dysfunctional symbiosis between the parallel system of public and private health care which has created the paradox of free public healthcare operating in tandem with an ever-expanding and expensive private healthcare industry, (Trinidad and Tobago Express [6]). One view is that no government has been able to unknot the myriad ways in which the privately owned medical sector has established itself as a profitable industry on the back of the failures of the free, taxpayer-funded public health system. Opening up a medical corridor between Trinidad and Tobago and Cuba may well be a solution to that problem, (Trinidad and Tobago Express [6]).

Trinidad and Tobago's health sector is hierarchically organized. The Minister of Health has overall responsibility for the Ministry of Health $(\mathrm{MoH})$. In Trinidad and Tobago, the $\mathrm{MoH}$ is the national authority charged with oversight of the entire health system. It plays a central role in the protection of the population's health and ensures that all organizations and institutions that produce health goods and services conform to standards of safety, (Government of the Republic of Trinidad and Tobago [7]). In addition, it claims that responsibility for the provision of health care services in Trinidad and Tobago was devolved from the $\mathrm{MoH}$ to Regional Health Authorities (RHAs) with the passing of the Regional Health Authorities Act No.5 of 1994. RHAs are autonomous bodies that own and operate health facilities in their respective regions, (Government of the Republic of Trinidad and Tobago [7]).

At present there are five (5) RHAs which deliver public health care services to the population. These are Eastern Regional Health Authority (ERHA), North Central Regional Health Authority (NCRHA), North West Regional Health Authority (NWRHA), South West Regional Health Authority (SWRHA) and Tobago Regional Health Authority (TRHA), (Government of the Republic of Trinidad and Tobago [7]).

SWOT Analysis is a tool used for strategic planning and strategic management in organizations. It can be used effectively to build organizational strategy and competitive strategy, (Gürel and Tat [8]). In accordance with the System Approach (SA), organizations are viewed as wholes that interact with their environments and consist of various sub-systems, (Gürel and Tat [8]). In this sense, an organization exists in two environments, one being in itself and the other being outside itself. It is a necessity to analyze these environments for strategic management practices, (Gürel and Tat [8]). The process of examining the organization and its environment is termed SWOT Analysis (Gürel and Tat [8]). Partial SWOT analysis is an analysis of one, two or three of its four components. This study analyzed the weaknesses of Trinidad and Tobago's health system. An important point of departure from SWOT analysis is this study's limitation that is, the absence of recommendations for strategic planning and management.

\section{Literature Review}

The review of literature is limited due to the dearth of academic research on the 
problems facing the public healthcare system in Trinidad and Tobago. However, some information on health care challenges is available in newspapers particularly in editorials and letters to editors. This review contains some challenges facing Trinidad and Tobago's health sector in particular and the Caribbean in general. Moreover, it examines some challenges faced in more developed countries such as the United States, Canada and China.

Bahall [9] suggests that over the last few decades Trinidad and Tobago's health services have been plagued by inefficiencies partly emanating from poor throughput processes. He argues that reports from numerous commissions, hospital administrators, and healthcare providers have alluded to inefficiencies and poor throughput processes. Furthermore, Bahall [9] states that in 1970, the editorial of a daily newspaper reported that a full-scale enquiry into the concern was needed, since the crisis in the nation's health services seems to be getting dangerously close to the point of total collapse, (Bahall [9]).

In another study, Bahall [10] notes that the health environment was inequitable in terms of accessibility gaps in public policy, public health, and secondary services which warrant out-of-pocket funding. He purports that out-of-pocket funding for basic services which the poor cannot manage or can only pay at a tremendous burden; gives an unfair advantage to others who can access more expensive and advanced services. Bahall [10] contends that poor public health and ambiguous public policies further disadvantage patients of low socio-economic status, resulting in access inequity, (Bahall [10]).

Bahall's [10] claim of inequity in health has been supported by The Trinidad and Tobago Guardian Newspaper. The newspaper claims that long waits for medical attention and for surgeries, no beds, poor healthcare, verbal abuse, negligence and prescriptions not filled in a timely manner are some of the major complaints levied by sick patients and their families against public health institutions. It explains that complaints are evident in numerous media reports. Also it suggests that inefficiency has led many ill citizens to choose a positive hospital over a public one, once they can afford it, (Trinidad and Tobago Guardian Newspaper [11]).

Gulliford [12] outlines past and present health conditions in the West Indies and describes the system of health care and some of the problems it faces at present. He argues that the last 30 years have seen a transition from a pattern of high childhood mortality to high mortality from chronic non-communicable diseases, such as diabetes, in adult life. However, he says that over the last 10 years the severity of economic conditions had undermined this progress, with the threatened re-emergence of malnutrition and infectious diseases as important health problems. Gulliford [12] claims that although most people in the region have access to health care, the quality and outcomes of care may be compromised by financial constraints and an unresponsive management system. Finally, Gulliford [12] suggests that adopting modern approaches to planning and managing the health system might be one path to improvement. 
Corruption is one problem confronting the healthcare system in the US. Vian [13] suggests that there is increasing interest among health policymakers, planners and donors on the effects of corruption on health care access and outcomes, and measures to combat corruption in the health sector. Biased distribution of infrastructure favoring urban- and elite-focused services, and high technology were two areas in which corruption was associated. Two additional problems are: 1) patients do not get proper treatment and 2) patients must make informal payments to obtain drugs. Other problems include: sub-therapeutic or fake drugs are allowed on the market, increased incidence of food poisoning and the spread of infectious and communicable diseases, (Vian [13]).

Bliemel and Hassanein [14] claim that healthcare in Canada is facing many problems. The most publicized symptoms are excessive waiting times for patients, lack of access, high cost of delivery and medical errors. They contend that e-health has been introduced as a potential solution for such problems. In a study of unmet health needs in Canada, Sibley and Glazier [15] found that unmet need due to unavailability was most likely to be experienced in Quebec, Newfoundland and Manitoba. Also, Sibley and Glazier [15] claim that Alberta and British Columbia had the highest likelihood of unmet need due to accessibility problems and that in British Columbia, Saskatchewan and Manitoba patients were more likely to report problems of acceptability, (Sibley and Glazier [15]).

Jamison et al. [16] believe that the burden of China's health problems has been transferred to the older age groups who are particularly vulnerable to chronic diseases. They contend that children's health challenges persist because in some rural areas children continue to suffer from moderate-to-serious malnutrition. These claims were based on the findings of a World Bank rural health and medical education mission that visited China for four weeks during the months September and October of 1982, (Jamison et al. [16]). More recent research on China's health challenges reveal that limited improvements have been achieved due to aggregate high-level health outcomes, e.g. infant mortality, (Ling et al. [17]). They identified a second problem-large and widening health inequalities associated with disparate wealth between provinces and a rural-urban divide. In addition, Ling et al. [17] suggest a third problem-that is, the burden of disease is shifting from predominantly communicable diseases to chronic diseases. Ling et al. [17] noted three reasons for the limited gains from investment in healthcare. They are increased out-of-pocket expenditure including a high proportion of catastrophic expenditure, a geographical imbalance in healthcare and the commercialization of healthcare without adequate attention to cost control which has led to the escalation of prices and decreased efficiency, (Ling et al. [17]).

\section{Methodology}

The study was conducted in East Trinidad. All participants were over 18 years 
and were selected as they walked in a busy street in Tunapuna, a main town. Fifty-six (56) potential participants were observed and approached based on facial approachability-the extent to which they seemed friendly and approachable. Of this number only 20 consented to participate based on convenience (the amount of free time they had). Semi-structured interview techniques were employed. E.g. some participants were probed more, because of time and willingness to engage in conversation. They were asked one main question: what do you think is the major problem facing public healthcare in Trinidad and Tobago? Probing or follow-up questions included: what is the reason for your choice of problem? How certain are you that only the lower classes experience this problem? Do you know the history of RHAs? Do you know where each is located? Can you describe the way T\&T's healthcare system is managed? Do you have any solutions for minimizing the problem you identified? At the end of each interview informants were debriefed and thanked for participating. The data were recorded by note-making, using jottings, immediately after interviews. The data were analyzed using a hybrid of a priori and inductive codes. The main a priori codes were technology, professionalism, accessibility and affordability. Through inductive coding abstract themes were developed by interpreting multiple codes that equated with long waiting time, inadequate health financing, poor maintenance and social inequality. By keeping an audit trail, employing member checking and engaging in reflexivity, the validity and reliability of the data were strengthened. Member checking occurred when five participants who consented to provide a phone contact were invited to validate my interpretation of their experience. Through researcher reflexivity notes were reviewed to ensure rich thick description of phenomena. My own knowledge was "bracketed" as the notes were read multiple (at least five) times. Intra-coder reliability ensured that themes were interpreted and named consistently.

\section{Findings}

Some demographic characteristics of the sample were recorded. Most participants reported that their main experiences of the public health system were gained by providing care for an elderly relative such as a grandparent or a young dependant-a baby, toddler or child. All informants claimed that they had little long term (more than one year) firsthand experience in public health care such as prolonged hospitalization and persistent health issues. Overall, participants possessed little knowledge of the internal working of the public health system. For example, they could not explain the management of RHAs and the role of the MoH. Also, they did not know the history of and geographical boundaries of the four (4) RHAs in Trinidad. Four (4) central problems facing the health sector were identified. The most frequently cited was long waiting time (20). This was followed by inadequate health financing (5), poor maintenance (3) and social inequality (1). Suggestions to overcome these challenges were suggested. All problems were examined in reference to the "primary effects of stratification". 
Even though a priori themes were validated, technology, professionalism, accessibility and affordability, for the most part, were examined within the main themes; long waiting time, inadequate funding, poor maintenance and social inequality.

\subsection{Demographic Characteristics}

Of 56 persons approached 37 were female and 19 were male. The sample consisted of 16 females and four (4) males. In general females were more facially approachable; their smile and pleasant demeanor indicated greater likelihood that they were willing to converse with me. Most (18) were younger than 50 years. Twelve female and all male informants were younger than 25. The remaining four (4) females were between 25 and 55. Thirteen participants identified with Christianity, three with Hinduism, two with Islam and two with none; even though they claimed to believe in God. Eleven (11) informants lived in East Trinidad (Tunapuna, St. Augustine, St. Joseph, San Juan and Barataria), five (5) lived in West Trinidad (Diego Martin, Carenage and Port of Spain) and three (3) lived in Central Trinidad (Cunupia, Enterprise and Las Lomas). Only one (1) participant lived in Penal, South Trinidad.

\subsection{Long Waiting Time}

Some participants discussed two or more problems e.g. waiting time and inadequate health financing which they thought could not be delinked. Long waiting time was expressed in several ways: patients sitting for a long time before they were attended to, doctors and nurses doing nothing while patients waited for attention, patients made to wait long because of health professionals' fear of contracting a contagious disease from a patient, poor communication between staff and patients and shortage of specialist doctors and nurses to diagnose and treat diseases. The problem of long waiting time for healthcare was attributed to the power imbalance between health providers and patients. Some participants concluded that often some public healthcare providers made decisions without patient or family involvement. Power imbalance was thought to be detrimental to patients in urgent need of medical care, particularly in emergency departments (EDs). They argued that in EDs, the young and the elderly were vulnerable to the health provider monopolizing power.

Some informants believed that by asking questions such as "when would I see a doctor?", "what is wrong with me?", that they were perceived to be impatient and disrespectful to nurses. They suggested that for seeking information they were overlooked i.e. missed their turn purposefully. Three (3) females opined that on a few occasions male patients received preferential treatment, that is, shorter waiting time. Some participants were fatalistic as they attributed long waiting time to their overall low status or lower class position in the stratification system. They felt that negative health provider perception and poor treatment stemmed from their powerlessness. Long waiting time impacted access to 
health care negatively.

\subsection{Inadequate Health Financing}

Government was blamed for insufficient spending on the public health system. While most participants had no idea of the amount of the National Budget alocated to health, they purported that not enough was spent on health technology. Technology shortage was the most commonly cited challenge e.g., limited numbers of ventilators and life support machines. MRI and CT scanners too, were thought to be in short supply. It was felt that public health facilities were ill-equipped. Also it was pointed out that sometimes private health facilities could not care for patients needing palliative care and having severe orthopedic injuries. Babies born prematurely who needed long term hospitalization were disadvantaged too. In these instances they quipped that the public healthcare system was the default health system. This, they believed put a strain on its resources. Ten (10) informants claimed that limited funding was exacerbated by dependence on developed nations for most of the health technology used in public health facilities. They affirmed that coupled with dependence on technology, inadequate state funding retarded quality health care. The dominant belief was that under funding occurs because the public health sector caters chiefly for the poor and lower classes. Participants opined that state officials paid less attention to the health needs of the poor. This, they claimed, was demonstrated by limited spending on health. It was suggested on two (2) occasions that pilferage from public health facilities may, in part, account for shortage/limited availability of medical technology in public health facilities. In other words, shortages could not be attributed only to limited state funding.

Limited health financing was associated with human resource challenges and affordability, the ability to pay for private curative health care. Human resource challenges included shortage of specialist doctors and nurses such as palliative care professionals, social workers, radiographers and psychiatrists. Participants affirmed that there were few centers where professional palliative care could be obtained. They stated that the main private centers are located in North West, Trinidad and that their services are not readily affordable to low income patients who earn less than TT $\$ 10,000$ monthly. They claimed that the major public palliative care center located in St. James (west of the capital, Port of Spain) is inadequate for the number of patients needing palliative care. A number of respondents argued that the wait time between appointments was too long for many ordinary persons who are unable to pay for private curative health care. Limited funding affected affordability most.

\subsection{Poor Maintenance}

The physical condition of some public health facilities was appraised negatively. The main complaint was that some were unkempt and did not appeal to patients who had to be hospitalized for one month or longer. Some facilities were 
thought to be in need of painting and repair. Most participants disapproved of the odor of some public health facilities which they compared unfavorably with the odor of private fee paying health facilities. Participants attributed this to poor or limited sanitization of public health facilities. Medical technology failed to impress most participants. Many felt that some ventilators and respirators were in decrepit condition and should be replaced. Waiting room and bathroom facilities were thought to be inadequate and in poor shape. Some participants bemoaned the poor facilities for parents who were impelled to remain with their sick children overnight. There was unanimous agreement that public health facilities were poorly maintained because they catered chiefly for the lower classes who were "powerless" to influence adequate state spending to maintain public health facilities. Poor maintenance was thought to affect accessibility the most.

\subsection{Social Inequality}

One (1) participant claimed that social inequality was a major problem in the public health care system. However, social inequality was perceived to be linked to all other problems or challenges: long waiting time, inadequate health financing and poor maintenance. She noted that lack of economic resources made it difficult for the less privileged to pay for private healthcare and that this subjected them to long waiting times, poor facilities and negative healthcare professional attitude and behavior. Also social inequality was linked to inadequate state funding. For this reason, it was opined that lower class patients tolerated poor quality service in public health facilities. It was pointed out that the more vulnerable such as the indigent and chronic poor suffering with rare or less frequently observed and diagnosed diseases (in the Trinidad population) such as cerebral palsy and Hodgkin's disease were less likely to access the highly specialized care they required. The main reason for this was a lack of specialist healthcare professionals and a lack of funding for advanced research on the prevalence and treatment of less common non communicable diseases. This informant claimed that her youngest son had to be taken to the US where he was diagnosed with T-cell non-Hodgkin lymphoma. The trip was possible only because her relatives residing in the US paid for it.

\subsection{Solutions}

Many participants believed that some medical doctors would not resort to engaging in private practice if they were better compensated monetarily. They stated that a greater supply of nurses and doctors would reduce waiting time significantly. This would make health professionals more available for patient care. Some informants claimed that government should spend more on developing indigenous health technology and maintaining existing medical technology. These two, they thought would lead to more efficient public health care. It was stated that greater spending on health facilities will create more aesthetically appealing environments for clients in instances of long waiting times. A few par- 
ticipants suggested that the private health system should reduce cost of care and make it more affordable for patients who are critically ill and are unable to access public health care in a timely manner. Participants proposed that during interaction with patients and visitors, healthcare professionals should be monitored closely. It was suggested that cameras should be installed in waiting rooms to capture health provider attitude and behavior towards patients and visitors. The dominant belief was that health care providers who know they are under scrutiny would adopt higher levels of professionalism and treat their clients more humanely. In addition it was felt that cameras would minimize pilferage of medical technology.

\section{Discussion}

Hypothetically speaking the findings demonstrate a relationship between social stratification and problems of access, availability, affordability and health outcome. Participants perceived that being lower class was responsible for the problems they faced in the health system. The findings support Hart's [5] thesis that the lower classes, in greater need of healthcare, are less likely to receive it.

It is clear that inadequate health financing, poor maintenance and social inequality were likely to affect access, availability, affordability and outcome. From this study it can be inferred that waiting time may impact accessibility and availability of healthcare most. Long waiting times were attributed to factors such as power imbalance between health providers and patients, and technology shortages. According to the Sunday Guardian [18] the WHO states that the nurse-patient ratio should be one to six. The Sunday Guardian claims that in Trinidad and Tobago, there was a "tremendous shortage" of staff, especially skilled medical staff including both doctors and nurses, at the public health institute, (Sunday Guardian [18]). It adds that the issue has reached "crisis" proportions throughout the country resulting in a ratio as high as 22 patients to one nurse at the San Fernando General Hospital (SFGH), (Sunday Guardian [18]). Furthermore it states that the situation at SFGH has resulted in long hours, excessive overtime, tired workers, and denial of legitimate leave. The newspaper states that this situation will "negatively impact the quality of health care to the population".

Whilst the Sunday Guardian [18] emphasized staff shortage as the major contributor to long waiting time, in this study participants did not consider the negative impact of staffing and other human resource challenges facing the health system. They associated long waiting time more closely with other problems: power imbalance, technology shortage, inadequate health financing, poor maintenance and social inequality. The problem of long waiting time is not unique to Trinidad and Tobago. In Canada, a more developed country, Bliemel and Hassanein [14] found that long waiting time was one symptom of that country's healthcare problems. In essence, challenges in accessing health care in Canada illustrate its impact on rich and poor countries alike. 
Similarly, limited funding of the health system was shown to be a significant problem for Jamaica. Inter Nations [19] states that not enough was spent on Jamaica's health system. In Trinidad and Tobago the 2017-2018 budget allocated TT $\$ 6.028$ billion to health, the third largest share after education (TT\$7.29 billion) and National Security (TT\$6.23 billion), (Trinidad Newsday [20]). Gouralal [21] shows that the allocation to health for 2018-2019 was similar to that of the previous year. In 2018-2019, Education and Training received TT\$7.392, National Security TT $\$ 6.120$ and Health TT $\$ 5.695$ billion. The total budget for 2018-2019 stood at TT $\$ 51.7$ billion. In spite of health's third rank in fiscal spending, participants claimed insufficient spending on health in general such as on technology, maintenance and innovation. Surprisingly corruption was not identified to be a problem facing Trinidad and Tobago's public health system. No support for Vian's [13] corruption thesis was found. In a future study it will be palpable to investigate allegations of corruption in Trinidad and Tobago's public health system.

Overall assessment of the results indicates striking similarities to the health care problems in more developed countries. Problems of long waiting time and limited health financing may require structural, economic and human resource reforms. For example, Gulliford's [12] argument that more modern approaches to planning and managing the health system might be one path to improvement. Adapted versions of management-by-objectives, risk-management, and performance management with full and equal participation from professionals and clients alike are some of the 'newer' approaches that may be implemented in Trinidad and Tobago in particular and in all countries in general, El Taguri [22].

\section{Conclusion}

A partial SWOT analysis or W-Analysis of the main weaknesses, challenges or problems facing the healthcare system of Trinidad and Tobago was performed. The GQM design was used with a sample of 20 persons ( 16 female and 4 male) who volunteered to participate. Sample recruitment occurred as persons walked in one of the main streets in Tunapuna, a major town in East Trinidad. Analysis of data revealed that the "primary effects of stratification" impacted problems of low access, weak availability and limited financing and poor maintenance in the public health system. This research aimed to understand participants' perspectives on the main challenges they experienced in the public healthcare system in Trinidad and Tobago. However, participants demonstrated that challenges were linked inextricably to the "primary effects of stratification." This means that being lower class or lower middle class and having less income to afford private curative healthcare led to an overwhelming feeling that they were made to wait long because public health professionals perceived that they depended on the public health system. In other words, they were made to wait because they could not afford alternative fee paying healthcare. Participants suggested that improvements can take place with greater monitoring of public health profession- 
als and with significant increases in public health financing and cost cutting by private health facilities.

\section{Conflicts of Interest}

The author declares no conflicts of interest regarding the publication of this paper.

\section{References}

[1] Praeg, P. (2015) Social Stratification and Health: Four Essays on Social Determinants of Health and Wellbeing. University of Groningen, Groningen.

[2] Roberts, S. (2018) Poverty and Health Sector Inequalities. https://www.scielosp.org/article/bwho/2002.v80n2/97-105/en/

[3] Wagstaff, A. (2002) Key Facts: Poverty and Poor Health. https://www.healthpovertyaction.org/news-events/key-facts-poverty-and-poor-heal th/

[4] United Nations Development Program (2018) Human Development Indices and Indicators: 2018 Statistical Update: Briefing Note for Countries on the 2018 Statistical Update Trinidad and Tobago.

http://hdr.undp.org/sites/all/themes/hdr theme/country-notes/TTO.pdf

[5] Hart, J.T. (1971) The Inverse Care Law.

https://www.sochealth.co.uk/national-health-service/public-health-and-wellbeing/p overty-and-inequality/the-inverse-care-law

[6] Trinidad and Tobago Express Newspapers (2018) Confronting the Health System's Paradox.

https://www.trinidadexpress.com/opinion/editorials/confronting-the-health-system -s-paradox/article ac89353e-9c34-11e8-8bba-0f16662f787c.html

[7] Government of the Republic of Trinidad and Tobago (2019) Ministry of HealthOverview. http://www.health.gov.tt/sitepages/default.aspx?id=38

[8] Gürel, E. and Tat, M. (2017) SWOT Analysis: A Theoretical Review. http://www.sosyalarastirmalar.com/cilt10/sayi51_pdf/6iksisat_kamu isletme/gurel emet.pdf https://doi.org/10.17719/jisr.2017.1832

[9] Bahall (2018) Health Services in Trinidad: Throughput, Throughput Challenges, and the Impact of a Throughput Intervention on Overcrowding in a Public Health Institution. BMC Health Services Research, 18, 129. https://doi.org/10.1186/s12913-018-2931-2

[10] Bahall, M. (2015) Health Equity and Access to Health Care in Trinidad and Tobago. World Journal of Public Health, 3, 83-92. https://doi.org/10.11648/j.wjph.20180303.13

[11] Trinidad and Tobago Guardian Newspaper (2015) 65 \% Not Happy with Govt Management of Healthcare.

http://www.guardian.co.tt/news/65-not-happy-govt-management-healthcare-6.2.36 $\underline{1763.017331 \mathrm{db} 3 \mathrm{e}}$

[12] Gulliford, M.C. (1994) News from Overseas: Health and Health Care in the English-Speaking Caribbean: A British Public Health Physician's View of the Caribbean. Journal of Public Health, 16, 263-269.

https://academic.oup.com/jpubhealth/article-abstract/16/3/263/1532235?redirected 
$\underline{\text { From }=\text { PDF }}$

[13] Vian, T. (2008) Review of Corruption in the Health Sector: Theory, Methods and Interventions. Health Policy and Planning, 23, 83-94.

https://doi.org/10.1093/heapol/czm048

https://academic.oup.com/heapol/article/23/2/83/590549

[14] Bliemel, M. and Hassanein, K. (2000) E-Health: Applying Business Process Reengineering Principles to Healthcare in Canada. International Journal of Electronic Business, 2, 625-643.

http://citeseerx.ist.psu.edu/viewdoc/download?doi=10.1.1.462.3060\&rep=rep1\&type $=\mathrm{pdf}$

[15] Sibley, L.M. and Glazier, R.H. (2009) Reasons for Self-Reported Unmet Healthcare Needs in Canada: A Population-Based Provincial Comparison. Health Policy, 5, 87-101. https://www.ncbi.nlm.nih.gov/pmc/articles/PMC2732657 https://doi.org/10.12927/hcpol.2009.20934

[16] Jamison, D.T., Evans, J.R., King, T., Porter, I., Prescott, N. and Prost, A. (1984) China: The Health Sector. World Bank, Washington DC.

https://www.popline.org/node/415054

[17] Ling, R.E., Liu, F., Lu, X.Q. and Wang, W. (2011) Emerging Issues in Public Health: A Perspective on China's Healthcare System. Public Health, 125, 9-14. https://www.ncbi.nlm.nih.gov/pubmed/21168175 https://doi.org/10.1016/j.puhe.2010.10.009

[18] Sunday Guardian (2016) Hospitals at Crisis Point. https://www.guardian.co.tt/news/hospitals-crisis-point-6.2.356092.046984917a

[19] InterNations (2018) A Practical Guide to the Way of Life in Jamaica. https://www.internations.org/go/moving-to-jamaica/living

[20] Trinidad Newsday (2017) Budget Documents. https://newsday.co.tt/2017-2018-budget

[21] Ghouralal, D. (2018) Budget 2019: 10 Highlights of the $\$ 51.7$ b Budget. http://www.looptt.com/content/budget-2019-10-highlights-517-b-budget

[22] El Taguri, A. (2008) Essential Concepts in Modern Health Services. Libyan Journal of Medicine, 3, 148-155. https://www.ncbi.nlm.nih.gov/pmc/articles/pmc3074271 